\title{
PYROLYSIS BEHAVIORS OF WASTE COCONUT SHELL AND HUSK BIOMASSES
}

\author{
Q. WANG \& J. SARKAR \\ Graduate School of Science and Engineering Saitama University, Japan.
}

\begin{abstract}
Coconut shell and husk are two biomasses wastes abundant in most of the coastal countries. However, despite their enormous potential as energy sources, they are hardly studied and their thermal characteristics are still not well known. In this study, both biomasses are thermally degraded through thermogravimetry (TG-DTA) and their pyrolysis product yield such as char, tar and gases are analyzed. The TG-DTA results show that pyrolysis of biomass consists of three stages. Three stages can be outlined as: (1) dehydration process for temperatures below $122^{\circ} \mathrm{C}$, (2) pyrolytic cracking from $122^{\circ} \mathrm{C}$ to $400^{\circ} \mathrm{C}$, stage consist of two exothermic simultaneous processes where hemicelluloses, cellulose and lignin are decomposed and a high amount of volatile matter formation occurs and (3) the last endothermic decomposition of the lignin at temperatures above $400^{\circ} \mathrm{C}$. From the pyrolytic results, it is showed that the char and gases yields were increased with the decrement tar. The gas-evolving profiles from pyrolyzing the coconut shell and husk components in a packed bed, monitored by a GC-TCD and a GC-FID, showed similar behavior. $\mathrm{H}_{2}$ was released out at a higher temperature $\left(>450^{\circ} \mathrm{C}\right)$ and it got the maximum rate at $700^{\circ} \mathrm{C}$ then it decreased. $\mathrm{CO}_{2}$ was released out at $130^{\circ} \mathrm{C}-750^{\circ} \mathrm{C}$ and got the maximum releasing value at $300^{\circ} \mathrm{C}-400^{\circ} \mathrm{C}$. The released $\mathrm{CO}$ showed almost similar pattern with that of $\mathrm{CO}_{2}$. However, the release rate was lower than $\mathrm{CO}_{2}$ and the maximum release rate of $\mathrm{CO}$ was found at $300^{\circ} \mathrm{C}$ $-400^{\circ} \mathrm{C} . \mathrm{CH}_{4}$ was released out at the temperature between $200^{\circ} \mathrm{C}-850^{\circ} \mathrm{C}$, and it got the maximum rate at $550^{\circ} \mathrm{C}$. The releasing of hydrocarbon was generally very low.

Keywords: biomass, fixed bed, pyrolysis, TGA, thermogravimetry.
\end{abstract}

\section{INTRODUCTION}

Modern energy enriches life. There are 7 billion people on earth who use energy each day to make their lives richer, more productive, safer and healthier. Energy is the driving force for the development of world economy. Due to the ever-increasing world population and the continually improving living standards, the demand for energy resources has risen dramatically, and this condition will continue. Fossil fuels such as petroleum, coal and natural gas satisfy the major fraction of total need of world's energy. However, the burning of fossil fuels causes greenhouse gas emission, which has many diver roles to the environment [1]. In addition, the world's oil supply is fixed since petroleum is naturally formed far too slowly in millions of years to be replaced at the rate at which it is being extracted [2]. Oil price also has increased over the years. As countries develop, industry and higher living standards drive up energy use, most often of oil. Thriving economies, such as India and China, are quickly becoming large oil consumers [3].

With the concern of depletion rate and price increase, there is rapidly growing interest in renewable energy source like biomass to be used as an alternative to fossil fuel. Biomass is biological material from living, or recently living organisms, most often referring to plants or plant-derived materials. Biomass can be converted to higher value products or energy. They include wide range of materials such as: virgin wood from forestry, energy crops specially grown for energy applications, agricultural residues from agriculture harvesting, food waste from food and drink preparation and processing, and post-consumer waste, or industrial waste and co-products from manufacturing and industrial processes [4].

The conversion technologies for utilization biomass can be separated into four basic categories: direct combustion processes, thermochemical processes, biochemical processes and 
agrochemical processes [5]. Biomass conversion techniques including thermo-chemical and biochemical conversion are employed for power generation and production of liquid biofuels, chemicals and charcoal, which can be used as activated carbon and bio-energy.

Thermo-chemical conversion processes use heat or chemicals to convert biomass into another chemical form. Some of the basic techniques are: combustion, pyrolysis and gasification. These techniques are separated principally by the extent to which the chemical reactions involved are allowed to proceed. That is mainly controlled by the availability of oxygen and conversion temperature.

The coconut palm, Cocos nucifera, is a member of the family Arecaceae (palm family). It is the only accepted species in the genus Cocos. The conditions required for coconut trees to grow without any care are: mean daily temperature above $12^{\circ} \mathrm{C}-13^{\circ} \mathrm{C}\left(53.6-55.4^{\circ} \mathrm{F}\right)$ every day of the year [6]. Coconut palms are grown in more than 90 countries of the world, with a total production of 62 million tons per year [7]. Bangladesh has about 2777 hectares of coconut land and the average annual coconut production is about 450000 metric tons [8]. The husk and shells can be used for fuel and are a source of charcoal, which is an attractive source of syngas.

In the present study, we focused on the product yield and the gas formation behaviors during the pyrolysis of waste coconut shell and husk biomasses. The objective of this study is to gain a comprehensive understanding to the coconut shell and husk pyrolysis with focuses on the gas product releasing properties, thus facilitate to establish a universe model to simulate biomass pyrolysis based the coconut shell and husk compounds. It is favorable for the development of advanced biomass pyrolysis and gasification processes as bioenergy.

\section{MATERIALS AND METHODS}

\subsection{Materials}

In this experiment, coconut shell and husk were subjected to pyrolysis process. Coconuts were obtained from a local market of Jessore, located in Khulna division, Bangladesh. The shell and husk were separated from the coconuts and then the coconut shell and husk were sun dried for few days to remove the moisture content. After that dried coconut shell and husk samples were separately grounded and sieved to $<250 \mu \mathrm{m}$ by crusher (WB-1, $700 \mathrm{~W}$, Osaka chemical, Co. Ltd., Japan) and sieve shaker (AS200 DIGIT 50 Hz, Retsch Co. Ltd., Japan), respectively, and then were dried at room temperature exposing 1 hour in the laboratory atmosphere for getting air-dried samples (JIS-M8811). Proximate analysis and ultimate analysis were performed on air-dried sample. Proximate analysis (Ash, volatile matter, moisture and fixed carbon) was conducted in accordance with the JIS-M8813. Ultimate analysis was done using a CHN corder (MT-5 Yanaco, Co. Ltd., Japan). The fundamental analyses of the coconut shell and husk are given in Table 1.

Table 1: Ultimate proximate and ultimate analyses of coconut shell and husk.

\begin{tabular}{lllllllll}
\hline \multicolumn{4}{c}{ Proximate analysis } & \multicolumn{7}{c}{ Ultimate analysis } \\
\hline$[\mathrm{wt} \%]$ & $\mathrm{M}$ & A & V.M & F.C & H & C & N & O \\
\hline Shell & 7.82 & 0.23 & 79.91 & 12.04 & 4.5 & 39.2 & 0.2 & 55.9 \\
Husk & 9.96 & 2.23 & 72.60 & 15.21 & 5.4 & 48.95 & 0.4 & 43.1 \\
\hline
\end{tabular}




\subsection{Determination of chemical constituents}

The major chemical element of coconut shell and husk were discerned. These include holocellulose, lignin and extractives. The chemical characteristics of coconut shell and coconut husk were determined in accordance with the standards outlined in wise methods. In the beginning step, extractives for example oils, waxes and resins were determined. In this process, a Soxhlet extraction flask of 250-ml capacity and Soxhlet extraction tube, inside diameter 30-40 mm, capacity to top of siphon about $100 \mathrm{ml}$, height of siphon tube about $55 \mathrm{~mm}$ were used. This type is specified because siphoning is more rapid than extractors with higher siphon tubes. The Soxhlet extraction flask was filled with $50 \mathrm{ml}$ ethanol and $100 \mathrm{ml}$ benzene mixture and heat 6 hours at $90^{\circ} \mathrm{C}$ using steam bath. Placed 2.0 to 10 grams of the air-dry sample into a tared extraction thimble. Placed the extraction thimble with specimen in clean and dry Soxhlet extraction apparatus. Connect the Soxhlet extraction apparatus in upright position to a clean and dry round bottom extraction flask. Connect the flask to the extraction apparatus and start water flow to the condenser section. Adjust the heaters to provide a boiling rate which will cycle the specimens for not less than 24 extractions over 6-hour period. Then removed the flask from the apparatus and partially evaporate the solvent in the extraction flask to a volume of 20-25 ml. Transfer the extract to the tared weighing dish by washing with small amounts of fresh solvent. Handle the weighing dish with forceps or tongs. Evaporate the solvent to near dryness while in the chemical fume hood. Dry the dish and contents in an oven for 1 hour at $105^{\circ} \mathrm{C}$, cool in a desiccator, and weigh. Run a blank determination with the solvent used in the test. Evaporate $150 \mathrm{ml}$ of the solvent to dryness, and weigh the residue. Correct the weight of the dried extract by the weight of residue found. Calculate the extractive content as follows equation (1).

$$
\text { Extract, } \%=\left[\left(\mathrm{W}_{\mathrm{e}}-\mathrm{W}_{0}\right) / \mathrm{W}_{\mathrm{b}}\right] \times 100
$$

where $\mathrm{W}_{\mathrm{e}}=$ dry weight of extract, $\mathrm{W}_{\mathrm{p}}=$ oven-dry weight of biomass, $\mathrm{W}_{0}=$ dry weight of blank residue.

The determination of holocellulose was carried out in according to the wise method. In this process, take an Erlenmeyer flax and put $2.5 \mathrm{~g}$ extract removed sample. $150 \mathrm{ml}$ deionized water, $1 \mathrm{~g} \mathrm{NaClO}_{2}$ and $0.2 \mathrm{ml}$ acetic acid mixed with the sample. The flax was placed on a steam bath at $80^{\circ} \mathrm{C}$ with a $50 \mathrm{ml}$ Erlenmeyer flax inverted over the top of the large flax and allowed to react. After 1 hour, $1 \mathrm{ml}$ sodium chlorate and $0.2 \mathrm{ml}$ acetic acid is added to the solution. The process was repeated more than three times. Then solution was filter and holocellulose where be submitted in the filter. Then the filter was dried over night after, then cooled for 1 hour and weighted. Calculate the holocellulose as flow equation (2).

$$
\text { Holocellulose, } \%=\left[\left(\mathrm{H}_{\mathrm{e}}-\mathrm{H}_{0}\right) / \mathrm{H}_{\mathrm{b}}\right] \times 100
$$

where $\mathrm{H}_{\mathrm{e}}=$ dry weight of holocellulose, $\mathrm{H}_{\mathrm{b}}$ = weight of biomass, $\mathrm{H}_{0}=$ filter weight.

Lignin was analyzed using $\mathrm{H}_{2} \mathrm{SO}_{4}$ method. This method was performed with $1.00 \mathrm{~g}$ of airdried extract free sample in $15 \mathrm{ml}$ of $72 \% \mathrm{H}_{2} \mathrm{SO}_{4}$ in a $50 \mathrm{ml}$ flax. The reaction temperature was about $25^{\circ} \mathrm{C}$ and the biomass was thoroughly mixed into the $72 \% \mathrm{H}_{2} \mathrm{SO}_{4}$ at the beginning. A glass rod was used and it was not removed from the flax until the end of the reaction stage. Kept this mixture for 4 hour in room temperature. After 4 hour mixture was placed in a 1000$\mathrm{ml}$ tringle flax and $560 \mathrm{ml}$ pure water was added. The solution was heated at $100^{\circ} \mathrm{C}$ for $4 \mathrm{~h}$. After that the solution was cooled in room temperature and filtered using glass filter 1GP 16 
and lignin was submitted in the filter. Then the filter was dried over night and after that cooled for 1 hour and weighted. Calculate the lignin as flow equation (3).

$$
\operatorname{Lignin} \%=\left[\left(\mathrm{L}_{\mathrm{e}}-\mathrm{L}_{0}\right) / \mathrm{L}_{\mathrm{b}}\right] \times 100
$$

where $\mathrm{L}_{\mathrm{e}}=$ dry weight of lignin, $\mathrm{L}_{\mathrm{b}}=$ weight of biomass, $\mathrm{L}_{0}=$ filter weigh.

\subsection{Pyrolysis behavior of coconut shell and husk using TG-DTA}

The pyrolysis of coconut shell and husk components were first carried using thermogravimetric differential thermal analyzer (TG-DTA). To mitigate the difference of heat and mass transfer, the sample weight was kept at $10 \mathrm{mg}$. The sample was heated up to $950^{\circ} \mathrm{C}$ at a constant heating rate of $10^{\circ} \mathrm{C} / \mathrm{min}$. Argon at a flow rate of $200 \mathrm{ml} / \mathrm{min}$ was used as the carrier gas to provide an inert atmosphere for pyrolysis and to remove the gaseous and condensable products, thus minimizing any secondary vapor-phase interactions. The conversion rate (x) was calculated from the weight loss measured using the TG-DTA and the initial weight. Weight loss was obtained from the conversion rate divided by the initial weight. The rate of the weight losses vs. time was expressed as $\mathrm{dx} / \mathrm{dt}$.

\subsection{Experimental apparatus for coconut shell and husk pyrolysis}

The design of the experimental setup used for coconut shell and husk pyrolysis and gasification is shown in Fig. 1. It was composed of gas feeding system, pyrolysis system, tar decomposition system, condensable products trapping system and gaseous products measurement system. Pyrolysis system and tar decomposition system consisted of the two stainless connecting reactors (inner diameter: $21.4 \mathrm{~mm}$, length: $500 \mathrm{~mm}$ ). Coconut shell and husk were placed on the mesh $(40 \mu \mathrm{m})$ in each reactor. This apparatus can be independently heated in two different electric furnaces while the gas mixture coming in contact with the samples. Therefore, heterogeneous reaction between tar and ash can be carried out using the apparatus. The lines between the first and second reactors as well as between the second reactor and the condensable products trapping the system were heated at the temperature of around $300^{\circ} \mathrm{C}-400^{\circ} \mathrm{C}$ to avoid the condensation of tar. The condensable products were collected by cooling the test tube, and the collection capability was improved by using glass beads. The

a: Flow meter

b: Heating furnace

c: Temperature controller

d: Reactor

e: Biomass sample

f: Ribbon heater

g: Ice water cooler

h: Light tar and water trap

i: $\mathrm{GC}-\mathrm{TCD}$

j: GC-FID

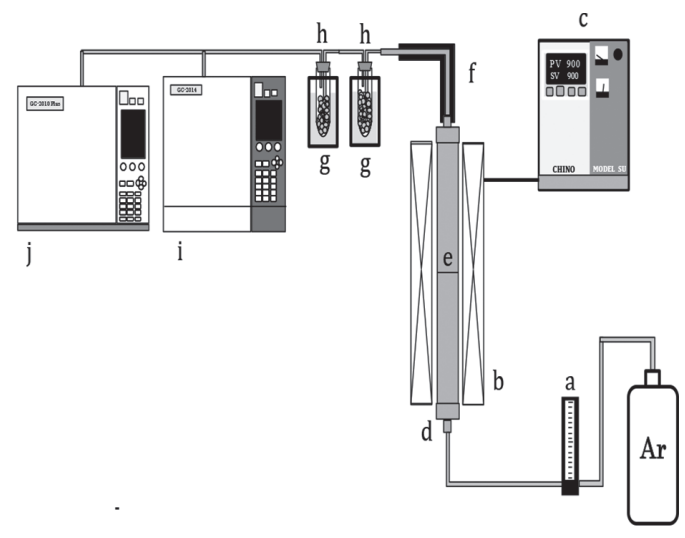

Figure 1: Experimental apparatus for pyrolysis products measurement. 
cooling bath was kept below $-3^{\circ} \mathrm{C}$ by mixing water and ice. The gaseous products were measured by a GC-TCD/FID (Model GC-2014; Shimadzu Co. Ltd., Japan). In this experiment, 10 kinds of gas were determined as gaseous products. $\mathrm{H}_{2}, \mathrm{CO}, \mathrm{CH}_{4}$ and $\mathrm{CO}_{2}$ were measured by a GC-TCD, while hydrocarbons $\left(\mathrm{C}_{2} \mathrm{H}_{6}\right.$ and $\mathrm{C}_{2} \mathrm{H}_{4}, \mathrm{C}_{3} \mathrm{H}_{8}, \mathrm{C}_{3} \mathrm{H}_{6}$, iso- $\mathrm{C}_{4} \mathrm{H}_{10}$, $n-\mathrm{C}_{4} \mathrm{H}_{10}$ ) were measured by a GC-FID.

\subsection{Measurement of pyrolysis product}

Coconut shell and husk samples were heated under Ar atmosphere at a heating rate of $10^{\circ} \mathrm{C} /$ min from room temperature (about $25^{\circ} \mathrm{C}$ ) to $900^{\circ} \mathrm{C}$. The produced gases in the pyrolysis of coconut shell and husk samples were measured every $80^{\circ} \mathrm{C}$ from $100^{\circ} \mathrm{C}$ to $900^{\circ} \mathrm{C}$. The produce of gaseous products $\left(\mathrm{H}_{2}, \mathrm{CO}, \mathrm{CO}_{2}, \mathrm{CH}_{4}, \mathrm{C}_{2} \mathrm{H}_{4}, \mathrm{C}_{2} \mathrm{H}_{6}, \mathrm{C}_{3} \mathrm{H}_{8}, \mathrm{C}_{3} \mathrm{H}_{6}, \mathrm{n}-\mathrm{C}_{4} \mathrm{H}_{10}\right.$, iso- $\left.\mathrm{C}_{4} \mathrm{H}_{10}\right)$ was calculated from the measurement results of GC-TCD (GC-2010, Shimadzu Co. Ltd., Japan) and GC-FID (Model GC-2014, Shimadzu Co. Ltd., Japan). The produce of tar was determined by the weight difference of the tar trap before and after the experiment. Tar contents are mainly present as 'light tar' and 'heavy tar' contents, considering that the light tar is collected in the tar trap and the heavy tar remained in the reaction tube. After completion of the experiment, open the electric furnace and cool the reaction tube for 1 hour using a fan. The produce of condensable product was determined by the weight difference of the tar trap before and after the experiment. After that, $20 \mathrm{ml}$ of 2-propanol was injected into the test tube to dissolve the condensable product and the water content of the sample was quantified by the Karl Fischer moisture measurement method. The amount of char was weight that remaining in the inside after removal of the reaction tube.

\section{RESULTS AND DISCUSSIONS}

3.1 Holocellulose and lignin contents in coconut shell and husk

Cellulose and lignin are generally recognized as the main components in biomass. Holocellulose (cellulose and hemicellulose) and lignin were determined by chemical analysis for coconut shell and husk. Figure 2 showed the cellulose and lignin contents in coconut shell

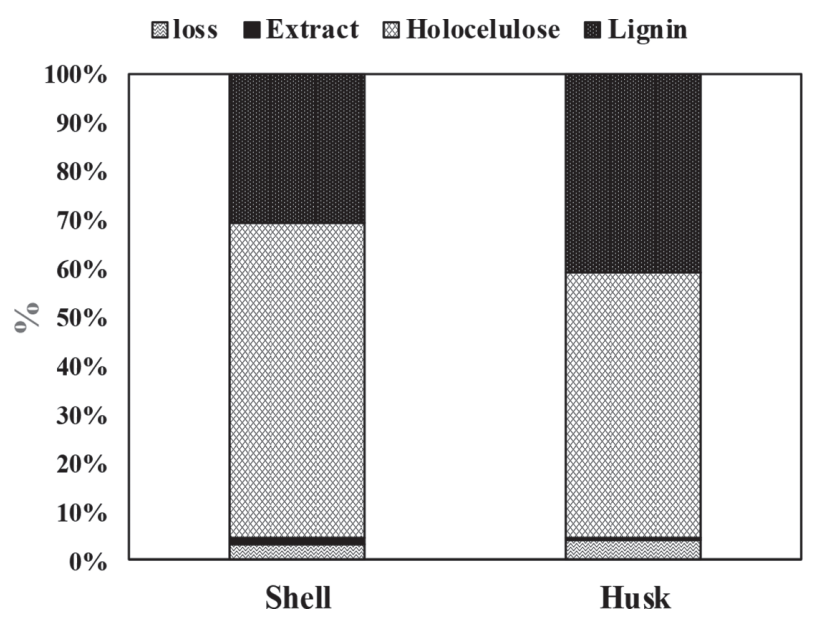

Figure 2: Cellulose and lignin contents in coconut shell and husk. 
and husk. The term holocellulose is composed of cellulose and hemicellulose. The weight fraction except for the cellulose and lignin fraction corresponds to the fraction of acid-soluble hydrocarbons in biomass. As shown in Fig. 2, coconut shell and husk samples contain more cellulose than lignin. The cellulose and lignin contents vary from 54\% to $65 \%$ and from $30 \%$ to $42 \%$, respectively. The shell contains the highest amount of cellulose, up to about $65 \%$ and husk has a maximum of lignin, up to about $41 \%$. Besides.

\subsection{Pyrolysis behavior of coconut shell and husk using TG-DTA}

Thermogravimetric analysis (TGA) records the loss of weight of a sample as the temperature is raised at a uniform rate. TGA of biomass samples has been extensively used as a means of determining the characteristics of the devolatilisation process. The TGA method provides information about net results of weight loss involving a range of complex chemical reactions in the thermal degradation of biomass. However, the data may be used to provide useful comparisons of the thermal degradation of different samples of biomass [9]. Thermal behavior of coconut shell and husk were studied by TG-DTA in the temperature range $20^{\circ} \mathrm{C}-950^{\circ} \mathrm{C}$. Pyrolysis of biomass consists of three stages (Fig. 3). These stages can be outlined as: (i) dehydration process for temperatures below $122^{\circ} \mathrm{C}$, (ii) pyrolytic cracking from $122^{\circ} \mathrm{C}$ to $400^{\circ} \mathrm{C}$, stage consist of two exothermic simultaneous processes where the main components, hemicelluloses, cellulose and lignin are decomposed and a high amount of volatile matter formation occur and (iii) the last endothermic decomposition of the lignin at temperatures above $400^{\circ} \mathrm{C}$. In first stage, as seen in Fig. 3 moisture removal stills up to $150^{\circ} \mathrm{C}$. The lignocellulosic part of the coconut shell and husk is stable until $230^{\circ} \mathrm{C}$ with minor losses of moisture and low molecular weight volatile matter. In the second stage, main components of coconut shell and husk, hemicelluloses and cellulose, start degradation within the temperature range of $230^{\circ} \mathrm{C}-400^{\circ} \mathrm{C}$. The weight loss was $60 \%$, which was due to break down of hemicelluloses and cellulose and volatile matter removal. White et al. [10] studied that decomposition of cellulosic part of biomass occurs in two ways. In the first way, which occurs at low temperatures (up to $400^{\circ} \mathrm{C}$ in this study), break down of bounds in polymers and formation of $\mathrm{CO}, \mathrm{CO}_{2}$ and carbonaceous were occurred. In the second way, at high

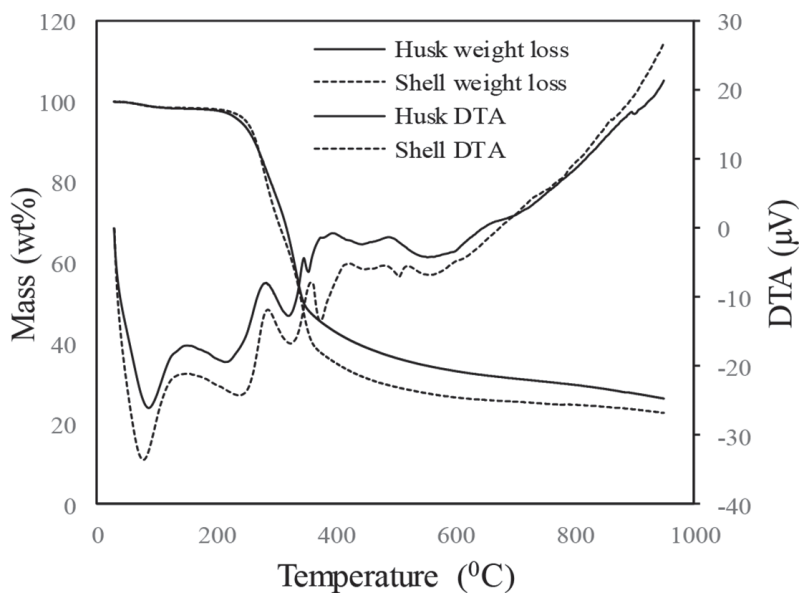

Figure 3: TG and DTA curves of coconut shell and husk. 
temperatures $\left(400^{\circ} \mathrm{C}-600^{\circ} \mathrm{C}\right.$ in this study) integration of bonds, which leads to liquid formation, takes place. In the third stage, lignin was the most difficult one to decompose among the three main components, whose decomposition happened slowly under the whole temperature range from ambient temperature to $950^{\circ} \mathrm{C}$, and the wide range of temperatures also caused the absence of its characteristic peak. Bilbao et al. [11] investigate that lignin volatilization occurs in a wide temperature range, which results a high char yield that maximizes at $460^{\circ} \mathrm{C}$. Weight loss between 400 and $700^{\circ} \mathrm{C}$ can be attributed to decomposition of tars. After $700^{\circ} \mathrm{C}$ only a small change in weight loss has been observed.

\subsection{Gases, tar and char yields obtained by pyrolysis}

Figure 4 showed the yields of products (char, gas, water and tar) for coconut shell and coconut husk during the pyrolysis at $900^{\circ} \mathrm{C}$. Coconut husk sample produced a much higher amount of char $(34.6 \%)$ than the coconut shell $(28.3 \%)$ during the pyrolysis. The result showed that more amounts of lignin produce more amounts of char, which was also observed at other biomass in the literature [12]. Among the biomass samples, coconut shell produced the largest amount of $\operatorname{tar}(25.5 \%)$ gas $(26.3 \%)$. On the other hand, coconut husk produced less tar, which were $17.3 \%$, respectively, and more amount of gas (26.9\%). Nakorn Worasuwannarak et al. [13] also analyzed other biomass and they found that higher content of cellulose produced the largest amount of tar. Moreover, all the samples produced almost same amount of $\mathrm{H}_{2} \mathrm{O}$ (i.e. $19.2 \%$ in coconut shell and $18.6 \%$ in coconut husk) during the pyrolysis. The much water content in the pyrolysis liquid product may be due to the release of volatile organic products during the preparation of condensed liquid tar sample. It is considerable that temperature conditions of the pyrolysis and gasification of tar are very important to reduce tar products for the pyrolysis and gasification processes [14-17] as bioenergy.

\subsection{Product gases yields obtained by gas chromatography}

The gas-evolving profiles from pyrolyzing the coconut shell and husk components in a packed bed, monitored by GC-TCD and GC-FID, are plotted in Figs 5 and 6. By comparison of Figs 5 and 6, almost similar points can be observed. $\mathrm{H}_{2}$ was released out at a higher temperature $\left(>450^{\circ} \mathrm{C}\right)$ and the releasing of $\mathrm{H}_{2}$ increased greatly with temperature increasing. For coconut shell and coconut husk, the releasing of $\mathrm{H}_{2}$ was significant and it got the maximum rate at $700^{\circ} \mathrm{C}$ after than the generation of $\mathrm{H}_{2}$ was decrease in the
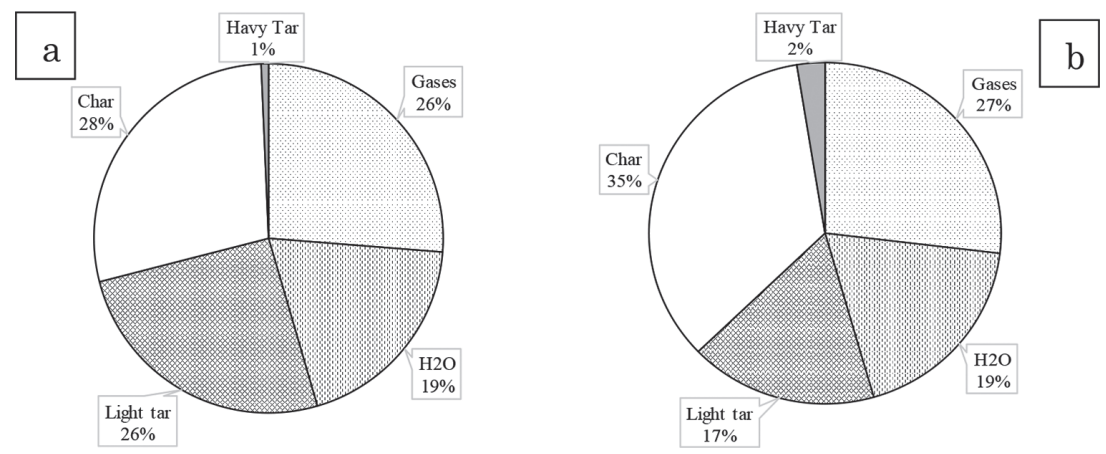

Figure 4: Pyrolysis products ratio of coconut (a) shell and (b) husk in Argon gas flow. 


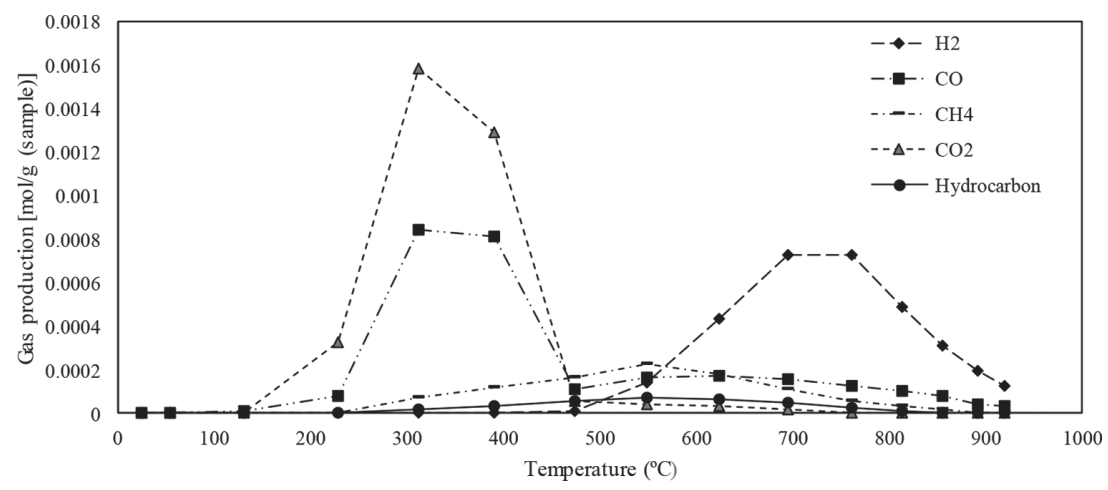

Figure 5: Releasing profile of gas products from coconut shell pyrolysis in Argon gas flow by heating at $10^{\circ} \mathrm{C} / \mathrm{min}$ to $900^{\circ} \mathrm{C}$.

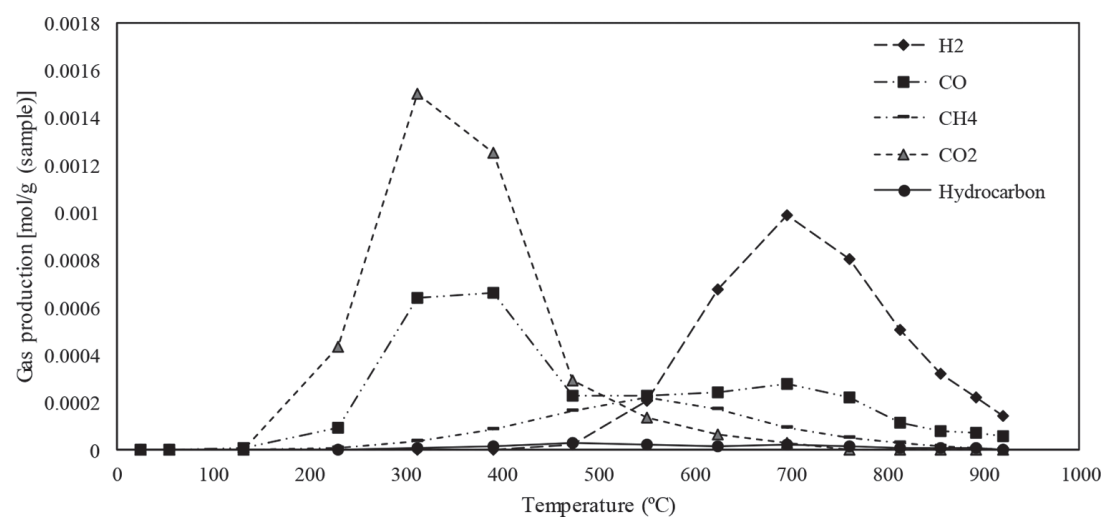

Figure 6: Releasing profile of gas products from coconut husk pyrolysis in Argon gas flow by heating at $10^{\circ} \mathrm{C} / \mathrm{min}$ to $900^{\circ} \mathrm{C}$.

temperature range. $\mathrm{CO}_{2}$ was released out at $130^{\circ} \mathrm{C}-750^{\circ} \mathrm{C}$ and got the maximum releasing value at $300^{\circ} \mathrm{C}-400^{\circ} \mathrm{C}$. The releasing of $\mathrm{CO}$ showed the almost similar pattern with that of $\mathrm{CO}_{2}$. However, its releasing rate was lower than $\mathrm{CO}_{2}$ and the maximum releasing rate of $\mathrm{CO}$ was found at $300^{\circ} \mathrm{C}-400^{\circ} \mathrm{C} . \mathrm{CH}_{4}$ was released out at the temperature range of $200^{\circ} \mathrm{C}-850^{\circ} \mathrm{C}$ and it got the maximum rate at $550^{\circ} \mathrm{C}$. The releasing of hydrocarbon was generally very low.

The yield of gas species from pyrolyzing the coconut shell and husk components are listed in Table 2. It was calculated by integrating the curve of gas product evolving rate in the whole temperature range $\left(25^{\circ} \mathrm{C}-900^{\circ} \mathrm{C}\right)$, thus it indicated the overall yield of each gas species from biomass pyrolysis. From the table, it can be observed that coconut shell owned the highest $\mathrm{CH}_{4}$ yield; it might be attributed to the higher content of aromatic ring and $\mathrm{O}-\mathrm{CH}_{3}$ functional groups in the origin coconut shell sample. On the other hand, coconut husk owned the highest $\mathrm{H}_{2}$. Production of $\mathrm{H}_{2}$ from organics pyrolysis mainly came from the cracking and deformation of $\mathrm{C}=\mathrm{C}$ and $\mathrm{C}-\mathrm{H}$, while $\mathrm{CH}_{4}$ was mainly brought by the cracking of methoxyl. Moreover, coconut husk obtained the highest $\mathrm{CO}$ and $\mathrm{CO}_{2}$ yield because of the higher carbonyl and carboxyl content. 
Table 2: Yield of gas product from coconut shell and husk pyrolysis.

\begin{tabular}{llllll}
\hline Sample & \multicolumn{6}{l}{ Gas production yield (mg/g-sample) } \\
\hline & $\mathrm{H}_{2}$ & $\mathrm{CO}$ & $\mathrm{CH}_{4}$ & $\mathrm{CO}_{2}$ & Hydrocarbons \\
\hline Coconut Shell & 6.4 & 76.0 & 15.5 & 147.3 & 9.7 \\
Coconut husk & 7.8 & 81.3 & 13.7 & 162.5 & 3.6 \\
\hline
\end{tabular}

\section{CONCLUSION}

In this study, pyrolysis experiments of the coconut shell and husk are carried out in TG-DTA and fixed bed reactor. The following are the findings from pyrolysis experiments of coconut shell in TG-DTA and fixed bed reactor:

1. The shell contains the highest amount of cellulose, up to about $65 \%$ and husk has a maximum of lignin, up to about $41 \%$ besides.

2. Main components of coconut shell and husk, hemicelluloses and cellulose, start degradation within the temperature range of $230^{\circ} \mathrm{C}-400^{\circ} \mathrm{C}$. The weight loss was $60 \%$, which was due to break down of hemicelluloses and cellulose and volatile matter removal.

3. Coconut husk sample produced a much higher amount of char $(34.6 \%)$ than coconut shell $(28.3 \%)$ during the pyrolysis. Among the biomass samples, coconut shell produced the largest amount of tar $(25.5 \%)$. On the other hand, coconut husk produced less tar, which was $17.3 \%$, respectively.

4. In the packed bed, $\mathrm{CO}_{2}$ and $\mathrm{CO}$ mainly evolved out at $130^{\circ} \mathrm{C}-750^{\circ} \mathrm{C}, \mathrm{H}_{2}$ evolved out at a higher temperature $\left(>450^{\circ} \mathrm{C}\right)$ and the yield of $\mathrm{H}_{2}$ increased with pyrolysis temperature increasing. The releasing of $\mathrm{H}_{2}$ was significant and it got the maximum rate at $700^{\circ} \mathrm{C}$ after than the generation of $\mathrm{H}_{2}$ was decrease in the temperature range. It was suggested that different chemical structures of biomass components attribute to different gas product releasing properties. Coconut husk displayed a higher $\mathrm{CO}$ and $\mathrm{CO}_{2}$ yield, mainly attributed to the thermal cracking of carbonyl and carboxyl content. With a higher presence of aromatic ring and methoxyl, the cracking and deformation of coconut shell released out much $\mathrm{CH}_{4}$.

\section{ACKNOWLEDGEMENT}

Some works of this study was supported by the special funds for Basic Researches (B) (No. 15H05119, FY2015 FY2017) of Grant-in-Aid Scientific Research of the Japanese Ministry of Education, Culture, Sports, Science and Technology (MEXT), Japan.

\section{REFERENCES}

[1] Asadullah, M., Rahman, M.A., Ali, M.M., Rahman, M.S., Motin, M.A., Sultan, M.B. \& Alam, M.R., Production of bio-oil from fixed bed pyrolysis of bagasse. Fuel, 86, pp. 2514-2520, 2007. https://doi.org/10.1016/j.fuel.2007.02.007

[2] Appenzeller, T., The end of cheap oil. National Geographic. June 2004.

[3] “China and India: A Rage for Oil”, Business Week, 25 August 2005.

[4] Biomass Energy Center. Available at: http://www.Biomassenergycentre.org.uk 
[5] Demirbas, A., Biomass resource facilities and biomass conversion processing for fuels and chemicals. Energy conversion and Management, 42(11), pp. 1357-1378, 2001. https://doi.org/10.1016/s0196-8904(00)00137-0

[6] Chan, E. \& Elevitch, C.R., Cocos nucifera (coconut) (version 2.1), 2006.

[7] Shashikumar, S. \& Chandrashekar, H.M., An analysis of production and marketing of coconut in Tumkur District, India. International Journal of Current Research and Academic Review, 2(10), pp. 167-175, 2014.

[8] Bangladesh Census of Agriculture, Department of Census and Statistics, 2011.

[9] Reed, A.R. \& Williams, P.T., Thermal processing of biomass natural fibre wastes by pyrolysis. International Journal of Energy Research, 28, pp. 131-145, 2004. https://doi.org/10.1002/er.956

[10] White, J.E., Catallo, W.J. \& Legendre, B.L., Biomass pyrolysis kinetics: a comparative critical review with relevant agricultural residue case studies. Journal Analytical and Applied Pyrolysis, 91(1), pp. 1-33, 2011. https://doi.org/10.1016/j.jaap.2011.01.004

[11] Bilbao, R., Mastral, J.F., Aldea, M.E. \& Ceamanos, J., The influence of the percentage of oxygen in the atmosphere on the thermal decomposition of lignocellulosic materials. Journal Analytical and Applied Pyrolysis, 42, pp. 189-202, 1997. https://doi.org/10.1016/s0165-2370(97)00050-8

[12] Burhenne, L., Messmer, J., Aicher, T. \& Laborie, M-P., The effect of the biomass components lignin, cellulose and hemicellulose on TGA and fixed bed pyrolysis. Journal of Analytical and Applied Pyrolysis, 101, pp. 177-184, 2013. https://doi.org/10.1016/j.jaap.2013.01.012

[13] Worasuwannarak, N., Sonobe, T. \& Tanthapanichakoon, W., Pyrolysis behaviors of rice straw, rice husk, and corncob by TG-MS technique. Journal Analytical and Applied Pyrolysis, 78, pp. 265-271, 2007. https://doi.org/10.1016/j.jaap.2006.08.002

[14] Wang, Q., Endo, T., Aparu, P. \& Kurogawa, H., Study on biomass tar reduction by ash and fluidizing medium in a heterogeneous reaction. International Journal of Sustainable Development and Planning, 9(5), pp. 669-679, 2014. https://doi.org/10.2495/sdp-v9-n5-669-679

[15] Wang, Q., Apaer, P., Kurokawa, H. \& Sugiyama, K., Reactivity for pyrolysis and CO2 gasification of alkali metal loaded waste wood char. International Journal of Sustainable Development and Planning, 9(5), pp. 680-691, 2014.

https://doi.org/10.2495/sdp-v9-n5-680-691

[16] Wang, Q., Niida, H., Liu, C., Kurokawa, H., Sarkar, A., Sekiguchi, K. \& Sugiyama, K., Oil aggregated behavior for coal recovery and combustion characteristics of their aggregates from different grade coals. International Journal of Sustainable Development and Planning, 9(5), pp. 692-704, 2014. https://doi.org/10.2495/sdp-v9-n5-692-704

[17] Wang, W., Aparu, P., Kurogawa, H. \& Sugiyama, K., Recovery briquetting technologies of waste biomass and pyrolyzed waste char produced from solid industrial and agricultural organic wastes. International Journal of Sustainable Development and Planning, 9(5), pp. 705-716, 2014. https://doi.org/10.2495/sdp-v9-n5-705-716 